\title{
Torque efficiency of square and rectangular archwires into 0.018 and 0.022 in. conventional brackets
}

\author{
Spyridon N. Papageorgiou ${ }^{1,2}$, losif Sifakakis ${ }^{3}$, loannis Doulis ${ }^{4}$, Theodore Eliades ${ }^{5^{*}}$ and Christoph Bourauel $^{2}$
}

\begin{abstract}
Background: The aim of this study was to compare the torque efficacy of square and rectangular wires in 0.018- and 0.022-in. conventionally ligated brackets.

Methods: Brackets of the same prescription were evaluated in both slot dimensions. Identical acrylic resin models of the maxilla were bonded with the brackets and mounted on the Orthodontic Measurement and Simulation System. Ten $0.018 \times 0.018$ in., $0.018 \times 0.022$ in., and $0.018 \times 0.025$ in. stainless steel wires were evaluated in the 0.018 -in. brackets and ten $0.019 \times 0.019$ in., $0.019 \times 0.025$ in., and $0.019 \times 0.026$ in. stainless steel wires were evaluated in the 0.022 -in. brackets. A $15^{\circ}$ buccal root torque was gradually applied to the right central incisor bracket, and the moments were recorded at this position. One-way ANOVA was applied for both bracket slot sizes along with post hoc analysis for the various archwire sizes.

Results: The mean measured moments varied between 10.78 and $30.60 \mathrm{Nmm}$ among the assessed wire-and-bracket combinations. Both square and rectangular archwires in the 0.018-in. bracket system exerted statistically significantly higher moments in comparison with their counterparts in the 0.022-in. bracket system. Rectangular archwires exerted statistically significantly higher moments than square archwires, both for the 0.018- and the 0.022-in. bracket system.
\end{abstract}

Conclusions: Rectangular archwires seem to be more efficient in torque exertion, especially in 0.018-in. brackets.

Keywords: Torque, Moments, 0.018-in. slot, 0.022-in. slot, Steel, Square archwires, Rectangular archwires

\section{Background}

Proper buccolingual inclination of both posterior and anterior teeth is essential to providing stability and proper occlusal relationship in orthodontic treatment. Torque of the maxillary incisors is particularly critical in establishing an esthetic smile line, proper anterior guidance, and a solid Class I relationship, because undertorqued anterior teeth can preclude the retraction of the anterior maxillary dentition. Suboptimal torque of the incisors can deprive the dental arch of space [1], while suboptimal torque of the posterior teeth might not allow appropriate cusp-to-fossa relationships between the maxillary and mandibular teeth [2].

\footnotetext{
* Correspondence: theodore.eliades@zzm.uzh.ch

${ }^{5}$ Clinic of Orthodontics and Paediatric Dentistry, Centre of Dental Medicine,

University of Zurich, Plattenstrasse 11, CH-8032 Zurich, Switzerland

Full list of author information is available at the end of the article
}

Torque expression is influenced by many factors, including the dimensions and material properties of the archwire and the bracket, the angle of twist of the archwire relative to the brackets, the mode of ligation, the bracket position, irregularities in tooth morphology, and beveling of archwires [3-8]. Slot size is another factor that could potentially influence torque expression. During slide mechanics, 0.022-in. brackets outperform 0.018 -in. systems but are inferior in torque expression $[9,10]$. With stainless steel archwires of $0.021 \mathrm{in}$. as the smaller dimension-close enough to the original 0.022-in. bracket slot size to provide full engagement of the bracket slot-springiness and range in torsion are so limited that effective torque with the archwire is essentially impossible. Alternatives that overcome this limitation include the use of nickel-titanium and $\beta$-Ti alloys, torquing auxiliaries, or smaller rectangular steel wires, for example, $0.019 \times 0.025 \mathrm{in}$., with increased activations. For this

\section{Springer}


reason, torque prescriptions of the 0.022 -in. brackets tend to be exaggerated, since heavy 0.021 - or 0.022 in. archwires may never be used in these brackets.

Currently, comparative data on square and rectangular data with regard to the generated moments at the final stages of the treatment is limited. Therefore, the aim of this study was to assess differences in the moments generated in the sagittal plane on a central incisor between square and rectangular stainless steel archwires in 0.018or 0.022-in. appliances.

\section{Methods}

\section{Experimental apparatus}

Generated moments (torque) at an upper central incisor was simulated in the Orthodontic Measurement and Simulation System (OMSS) (Fig. 1), a measuring device used widely in the literature for the quantitative evaluation of various orthodontic force systems [11]. Tooth movements can be simulated with this device in the three dimensions [12]. Two independent positioning tables, with six force/torque sensors each, are connected to the region of interest in order to measure the developed force and torque vectors, guided by a central personal computer.

\section{Configuration and materials}

High-torque 0.018- and 0.022-in. brackets from the same company (Mini 2000, ORMCO, Glendora, California, USA) were evaluated with a prescribed torque of $22^{\circ}$ and angulation of $5^{\circ}$ for the central incisor.
Two identical maxillary models with a leveled and aligned dental arch were constructed from acrylic resin, and each model was bonded with brackets up to the first premolars. An ideal passive $0.018 \times 0.025$ in. or a $0.021 \times 0.025$ in. stainless steel archwire was used for bonding the 0.018 - and the 0.022 -in. brackets, respectively. A torque-force sensor of the OMSS replaced the right central incisor, and the bracket was bonded directly on the sensor. At this configuration, an adjustment of the system was conducted with the abovementioned archwire in place and all forces/moments generated were nullified.

Ten specimens of $0.018 \times 0.018$ in., $0.018 \times 0.022$ in., and $0.018 \times 0.025 \mathrm{in}$. stainless steel archwires (ORMCO, Glendora, California, USA) were evaluated in the 0.018-in. brackets. In the 0.022-in. series, the measured archwires were ten $0.019 \times 0.019 \mathrm{in}$., ten $0.019 \times 0.025 \mathrm{in}$., and ten $0.019 \times 0.026$ in. stainless steel specimens (ORMCO, Glendora, California, USA). For the construction of all archwires, a photocopy of the model was used as a template. The archwires were ligated with 0.120-in. (Molded "O"; ORMCO, Orange, California, USA) elastomeric ligatures into the brackets. A $15^{\circ}$ buccal root torque was gradually applied to the right central incisor bracket, in steps of $0.5^{\circ}$ along the central axis of the slot. After each activation, the bracket was set to its initial position and the moments in the sagittal plane were recorded during the rotation of the bracket.

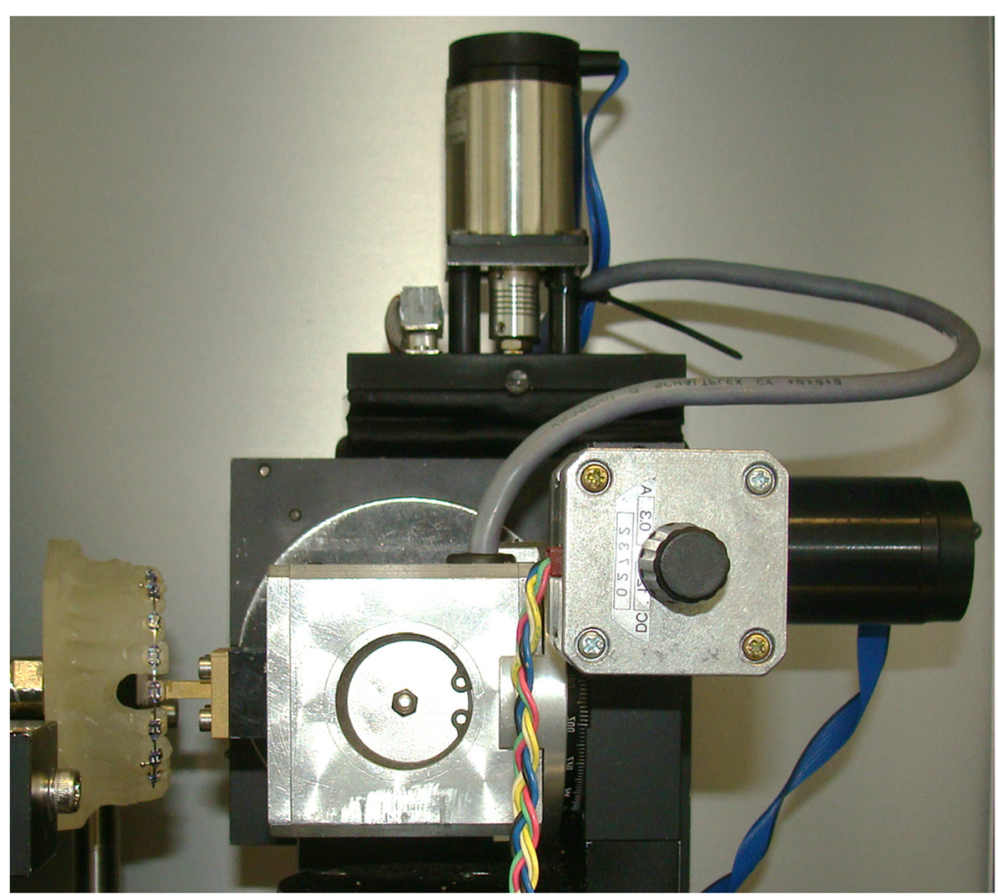

Fig. 1 The positioning table of the OMSS with the model mounted on it. Its torque-force sensor replaced the right central incisor 
After ligating each wire with new elastomerics, the measurement was repeated. The measuring range of the torquing moments in OMSS was $\pm 450 \mathrm{Nmm}$, and the torque threshold was $0.2 \mathrm{Nmm}$. The OMSS during the measurement cycles was installed in a temperaturecontrolled chamber (VEM 03/400, Vötsch Heraeus, Germany) [11].

\section{Statistical analysis}

The mean value of the two repeated measurements in every specimen of the generated moments was calculated at the maximum rotation. We conducted one-way analysis of variance (one-way ANOVA) with the mean torque as the dependent variable and archwire size as the independent/factor variable. One model was fitted for bracket slot $0.018 \mathrm{in}$. and one for $0.022 \mathrm{in}$. The three levels for the archwire size for the first model were $0.018 \times 0.018$ in., $0.018 \times 0.022$ in., and $0.018 \times 0.025$ in., while for the second model they were $0.019 \times 0.019$ in., $0.019 \times 0.025$ in. and $0.019 \times 0.026$ in. Post hoc analysis followed as multiple comparisons corrected with Sidak's method. Finally, we executed ANOVA diagnostics to test for the validity of all underlying model assumptions. The alpha level of statistical significance was set to $\alpha=0.05$. All statistical analyses were performed with the Stata 13 statistical software (Stata Corp, College Station, Texas, USA).

\section{Results}

In the 0.018-in. brackets, the mean maximum moment recorded at $15^{\circ}$ in the central incisor by the square $0.018 \times 0.018 \mathrm{in}$. archwire was $18.19 \mathrm{Nmm}(\mathrm{SD}=0.30)$. In the same configuration, but with a rectangular $0.018 \times 0.022 \mathrm{in}$. or a $0.018 \times 0.025 \mathrm{in}$. archwire, the measured mean moment was $22.93 \mathrm{Nmm}(\mathrm{SD}=0.68)$ and $30.60 \mathrm{Nmm}(\mathrm{SD}=0.37)$, respectively (Table 1$)$.

In the 0.022-in. brackets, the insertion of a square $0.019 \times 0.019$ in. archwire generated mean moments of $10.78 \mathrm{Nmm}$ in the central incisor $(\mathrm{SD}=0.86)$. The insertion of a rectangular $0.019 \times 0.025$ in. or a

Table 1 Mean values, standard deviation (SD) of moments $(\mathrm{Nmm})$ by type of bracket and wire

\begin{tabular}{llll}
\hline $\begin{array}{l}\text { Bracket slot } \\
\text { height (in.) }\end{array}$ & Cross-section & Wire (in.) & Moment mean (SD) \\
\hline 0.018 & Square & $0.018 \times 0.018$ & $18.19(0.30)$ \\
& Rectangular & $0.018 \times 0.022$ & $22.93(0.68)$ \\
& Rectangular & $0.018 \times 0.025$ & $30.60(0.37)$ \\
0.022 & Square & $0.019 \times 0.019$ & $10.78(0.86)$ \\
& Rectangular & $0.019 \times 0.025$ & $15.66(0.52)$ \\
& Rectangular & $0.019 \times 0.026$ & $16.51(0.48)$ \\
\hline
\end{tabular}

SD standard deviation
$0.019 \times 0.026$ in. archwire exerted a measured mean moment of $15.66 \mathrm{Nmm}(\mathrm{SD}=0.52)$ and $16.51 \mathrm{Nmm}$ $(\mathrm{SD}=0.48)$, respectively. One-way ANOVA rejected the null hypotheses that mean torque was equal for the three archwire sizes, a finding concerning both bracket slot sizes 0.018 in. and 0.022 in. (Tables 2, 3, 4 , and 5). The ANOVA results are shown at Tables 2 and 4. Post hoc analyses showed that torque exhibited a statistically significant increase by increasing archwire size for both bracket slot dimensions. Tukey's post hoc analyses are displayed at Tables 3 and 5 . Normality and homoscedasticity assumptions were not violated.

\section{Discussion}

The aim of this study was to assess the torque efficiency of square and rectangular stainless steel archwires in 0.018 - and 0.022-in. brackets. The results indicate that high-dimensional rectangular archwires exert significantly higher moments compared to square archwires. Additionally, 0.018-in. brackets were more torqueefficient than 0.022-in. brackets, regardless of archwire cross-section.

Rectangular archwires generated higher moments compared to square ones, both in the 0.018- and the 0.022-in. bracket slot system. This is in accordance with theoretical trigonometrical calculations of the torque play based on their nominal dimensions (Table 6) [13] and with experimental measurements of the actual torque play $[3,14,15]$.

Torque efficiency was significantly higher with 0.018-in. slot brackets than with 0.022 -in. brackets, independently of the archwire's cross-section. The maximum torque exerted from the $0.019 \times 0.025$ in. archwire in the 0.022 -in. brackets was about half of the value recorded from the $0.018 \times 0.025$ in. archwire in the 0.018-in. brackets. Between the evaluated square archwires, the magnitude of the recorded moment with a $0.018 \times 0.018$ in. archwire in 0.018 -in. brackets was

Table 2 ANOVA results for the effect of wire type on the generated moments on the central incisor for bracket slot size 0.018 in.

\begin{tabular}{llllll}
\hline $\begin{array}{l}\text { Number of } \\
\text { observations }\end{array}$ & 30 & & $R$-squared & 0.9921 & \\
Root MSE & 0.48 & & Adj R-squared & 0.9915 & \\
\cline { 2 - 4 } \cline { 5 - 6 } Source & Partial SS & Df & MS & $F$ & Prob $>F$ \\
\hline Model & 784.50 & 2 & 392.25 & 1689.13 & $<0.001$ \\
Wire & 784.50 & 2 & 392.25 & 1689.13 & $<0.001$ \\
Residual & 6.27 & 27 & 0.23 & & \\
Total & 790.77 & 29 & 27.27 & & \\
\hline
\end{tabular}

ANOVA analysis of variance, MSE mean square of the error, SS sum of squares, $D f$ degrees of freedom, MS mean square 
Table 3 Tukey's post hoc analysis for all pairwise comparisons among archwire sizes for bracket slot size 0.018 in.

\begin{tabular}{lcccc}
\hline $\begin{array}{l}\text { Comparison of } \\
\text { wires (in.) }\end{array}$ & Mean difference & HSD statistic & $p$ value & $\begin{array}{l}\text { Tukey's } \\
95 \% \mathrm{Cl}\end{array}$ \\
\hline $0.018 \times 0.018$ vs & 4.73 & 31.07 & $<0.001$ & {$[4.20,5.27]$} \\
$0.018 \times 0.022$ & & & & \\
$0.018 \times 0.018$ vs & 12.41 & 81.44 & $<0.001$ & {$[11.88,12.94]$} \\
$0.018 \times 0.025$ & & & & \\
$0.018 \times 0.022$ vs & 7.68 & 50.37 & $<0.001$ & {$[7.14,8.21]$} \\
$0.018 \times 0.025$ & & & & \\
\hline
\end{tabular}

$H S D$ honest significant difference, $\mathrm{Cl}$ confidence interval

almost double in comparison with a $0.019 \times 0.019$ in. archwire in the 0.022 -in. brackets. This fact may be explained by the lower torsional play of the final archwires used in the 0.018-in. slot brackets and agrees with previous data [16]. The difference between the $0.019 \times 0.025 \mathrm{in}$. and $0.019 \times 0.026 \mathrm{in}$. archwires in the 0.022 -in. brackets was small $(5 \%)$ and clinically insignificant. The difference between these archwires in polar molar of inertia and polar section modulus, which are proportional to stiffness and strength in torsion, respectively, is also small (7\%) [17].

According to Burstone, clinically relevant torque values range between 5 and $20 \mathrm{Nmm}$, with no tooth movement occurring under $5 \mathrm{Nmm}$, and values exceeding $20 \mathrm{Nmm}$ being associated with damage to the periodontal tissues and particularly root resorption [18]. The time of treatment with rectangular archwires contributes significantly to apical root resorption [19], and teeth that are moved for a longer time or with a higher magnitude of applied moments tend to show a higher degree of root resorption in width and depth [20]. Surprisingly, lower moment magnitudes were found to induce root resorption, too [21]. Root resorption is a multifactorial phenomenon with complex etiopathology, and no single mechanical factor like root torque can adequately cover this. Additionally, deformation of the periodontal ligament and the subsequently developed strains

Table 4 ANOVA results for the effect of wire type on the generated moments on the central incisor for bracket slot size 0.022 in.

\begin{tabular}{|c|c|c|c|c|c|}
\hline $\begin{array}{l}\text { Number of } \\
\text { observations }\end{array}$ & 30 & & $R$-squared & 0.9446 & \\
\hline Root MSE & 0.65 & & Adj R-squared & 0.9405 & \\
\hline Source & Partial SS & Df & MS & $F$ & Prob $>F$ \\
\hline Model & 191.42 & 2 & 95.71 & 230.05 & $<0.001$ \\
\hline Wire & 191.42 & 2 & 95.71 & 230.05 & $<0.001$ \\
\hline Residual & 11.23 & 27 & 0.42 & & \\
\hline Total & 202.65 & 29 & 6.99 & & \\
\hline
\end{tabular}

ANOVA analysis of variance, MSE mean square of the error, SS sum of squares, $D f$ degrees of freedom, MS mean square
Table 5 Tukey's post hoc analysis for all pairwise comparisons among archwire sizes for bracket slot size 0.022 in.

\begin{tabular}{lcccc}
\hline Comparison & Mean difference & HSD statistic & $p$ value & $\begin{array}{l}\text { Tukey's } \\
95 \% \mathrm{Cl}\end{array}$ \\
\hline $\begin{array}{l}0.019 \times 0.019 \text { vs } \\
0.019 \times 0.025\end{array}$ & 4.88 & 23.91 & $<0.001$ & {$[4.16,5.59]$} \\
$0.019 \times 0.019$ vs & 5.74 & 28.12 & $<0.001$ & {$[5.02,6.45]$} \\
$0.019 \times 0.026$ & & & & \\
$0.019 \times 0.025$ vs & 0.86 & 4.21 & $<0.001$ & {$[0.14,1.58]$} \\
$0.019 \times 0.026$ & & & &
\end{tabular}

HSD honest significant difference, $\mathrm{Cl}$ confidence interval

are theoretically influenced by the center of rotation and its relation to its center of resistance, which might not be constant, due to the varying degree of periodontal anisotropy [22]. A changing center of rotation during orthodontic movement is the rule rather than the exception; that is, different types of orthodontic movement might be involved in the movement path [23]. An additional detrimental factor for the development of root resorption might be the iatrogenous approximation of anterior tooth roots towards the palatal cortical plate [24, 25]. Additionally, torque values higher than $26 \mathrm{Nmm}$ have also been associated with plastic deformation of the bracket slot [26]. As a result, the present findings could be used for comparison purposes, but should not be regarded as the sole influencing factors on the ideal torquing efficiency of the various wire-bracket configurations.

In this study, stainless steel archwires were included, as the primary aim was to compare the torque efficiency between square and rectangular archwires. Stainless steel archwires generate higher moments compared with their $\beta$-Ti counterparts, in both slot systems [14, 27].

The wires evaluated in this study are most usually inserted as the final archwires during orthodontic treatment, and heavier archwires are rarely used [8]. In both bracket slot sizes, the measured moments generated by rectangular archwires were higher compared to the square archwires, due to torque loss. The torsional play of a $0.018 \times 0.025 \mathrm{in}$. archwire with nominal dimensions in 0.018 -in. systems could be theoretically estimated at approximately $0^{\circ}$ and at $7^{\circ}$ for a $0.019 \times 0.025 \mathrm{in}$.

Table 6 Theoretical torque loss for different square and rectangular archwires in 0.018- and 0.022-in. bracket slots (all with nominal dimensions-based on Dellinger [13])

\begin{tabular}{llll}
\hline Wire cross-section & Wire size (in.) & $\begin{array}{l}\text { Slot size } \\
\text { (in.) }\end{array}$ & $\begin{array}{l}\text { Calculated torque } \\
\text { loss (degrees) }\end{array}$ \\
\hline Square/rectangular & $0.018 \times 0.018 / 0.022 / 0.025$ & 0.018 & 0 \\
Square & $0.019 \times 0.019$ & 0.022 & 9.96 \\
Rectangular & $0.019 \times 0.022$ & 0.022 & 8.37 \\
Rectangular & $0.019 \times 0.025$ & 0.022 & 7.24 \\
\hline
\end{tabular}


archwire in the 0.022 -in. slot $[13,17,28,29]$. However, various experimental configurations revealed that torque play is actually higher than calculated, both in conventional [30-34] and self-ligating bracket systems [35-39]. The inconsistency in torque play assessments between theoretical calculations and experimental configurations could be attributed to dimensional inconsistency of archwire and bracket, as well as to rounded wire edges $[29,32,40,41]$. In addition, the bracket slot could be tapered slightly, resulting in further torque-loss fluctuations between archwires of different cross-sections [29]. As the OMSS configuration approximates the clinical situation, the torque loss is notably higher than in the in vitro activating experiments. This is due to additional torque play provided by the adjacent teeth [30], that is, the play both in the torque-receiving and in the torquedelivering bracket must be negated [42].

In the present study, the influence of the varying interbracket wire length [43] is negligible, as models and brackets among the assessed wire-bracket combinations were identical. Stiffness in torsion is inversely proportional to length; however, changes in wire length do not exert as high an influence on wire torsion as on wire bending [17].

Both wire types in this experiment were ligated with elastic ligatures. The effect of elastic/metal ligation type is not expected to influence torque magnitude in full slot size wires and in the $0.018 \times 0.025 \mathrm{in}$. steel archwire in the 0.018 -in. slot system. However, for the $0.019 \times 0.025 \mathrm{in}$. steel wire in the 0.022 -in. slot, the measured moment with elastic ligation could be $20 \%$ lower than with metal ligation at $5^{\circ}-15^{\circ}$ of torque, since the archwire may not completely seat during torquing [44]. The 0.120 -in. elastic ligatures presenting high seating force were used in this experiment in order to ensure the initial seating of the archwire with consistent and similar ligation forces between the different bracket systems $[45,46]$. Unfortunately, the main disadvantage of the elastic ligatures still remains their rapid force loss-which could exceed $50 \%$ in $24 \mathrm{~h}$-and consequently, this fact makes the engagement of the wire into the slot flexible and incomplete. In cases of maximum torque demands, steel ligatures should be preferred to provide increased torque expression $[2,45]$.

This study's results, as is with most in vitro studies, might not be directly extrapolated to clinical practice. This study has focused on the comparison of the initial force systems of specific bracket/archwire combinations, but the actual force system acting on the teeth will probably vary in time, due to the anisotropic periodontal ligament. Although OMSS can precisely simulate the initial tooth movement within the periodontium, additional factors like intraoral ageing of fixed appliances and the modifying role of saliva are not taken into account.

\section{Conclusions}

Square archwires produce lower torque magnitudes in comparison with rectangular archwires. This difference is exaggerated with a 0.018 -in. bracket slot system, in comparison with a 0.022 -in. slot system.

The most efficient archwire-bracket combination in terms of torque expression is the use of rectangular archwires in 0.018-in. brackets.

\section{Competing interests}

The authors declare that they have no competing interests.

\section{Authors' contributions}

IS, TE, and CB conceived and designed the experiment. IS and CB performed all measurements in the experimental setting. IS performed the analysis of data. SNP drafted the manuscript and IS, ID, TE, and CB revised the manuscript for important intellectual contents. All authors read and approved the final manuscript.

\section{Acknowledgements}

This work was supported by the German Academic Exchange Service (DAAD) (research grant no. A/14/01558). IS received a scholarship from DAAD (German Academic Exchange Service).

\section{Author details}

${ }^{1}$ Department of Orthodontics, School of Dentistry, University of Bonn, Bonn, Germany. ${ }^{2}$ Department of Oral Technology, School of Dentistry, University of Bonn, Bonn, Germany. 'Department of Orthodontics, School of Dentistry, National and Kapodistrian University of Athens, Athens, Greece. ${ }^{4}$ Hellenic Air Force General Hospital, Athens, Greece. ${ }^{5}$ Clinic of Orthodontics and Paediatric Dentistry, Centre of Dental Medicine, University of Zurich, Plattenstrasse 11, CH-8032 Zurich, Switzerland.

Received: 3 December 2015 Accepted: 8 January 2016

Published online: 15 January 2016

\section{References}

1. O'Higgins EA, Kirschen RH, Lee RT. The influence of maxillary incisor inclination on arch length. Br J Orthod. 1999;26:97-102.

2. Gioka C, Eliades T. Materials-induced variation in the torque expression of preadjusted appliances. Am J Orthod Dentofacial Orthop. 2004;125:323-8.

3. Sebanc J, Brantley WA, Pincsak JJ, Conover JP. Variability of effective torque as a function of edge bevel on orthodontic arch wires. Am J Orthod. 1984;86:43-51.

4. Germane N, Bentley Jr BE, Isaacson RJ. Three biologic variables modifying faciolingual tooth angulation by straight-wire appliances. Am J Orthod Dentofacial Orthop. 1989;96:312-9.

5. Miethke RR, Melsen B. Effect of variation in tooth morphology and bracket position on first and third order correction with preadjusted appliances. Am J Orthod. 1999;116:329-35.

6. Morina $E$, Eliades T, Pandis N, Jäger A, Bourauel C. Torque expression of self-ligating brackets compared with conventional metallic, ceramic, and plastic brackets. Eur J Orthod. 2008;30:233-8.

7. Huang Y, Keilig L, Rahimi A, Reimann S, Eliades T, Jäger A, et al. Numeric modeling of torque capabilities of self-ligating and conventional brackets. Am J Orthod Dentofacial Orthop. 2009;136:638-43.

8. Archambault A, Major TW, Carey JP. Heo G, Badawi H, Major PW. A comparison of torque expression between stainless steel, titanium molybdenum alloy, and copper nickel titanium wires in metallic self-ligating brackets. Angle Orthod. 2010;80:884-9.

9. Amditis C, Smith LF. The duration of fixed orthodontic treatment: a comparison of two groups of patients treated using edgewise brackets with 0.018" and 0.022" slots. Aust Orthod J. 2000;16:34-9.

10. Detterline DA, Isikbay SC, Brizendine EJ, Kula KS. Clinical outcomes of 0.018 -inch and 0.022 -inch bracket slot using the $A B O$ objective grading system. Angle Orthod. 2010;80:528-32.

11. Bourauel C, Drescher D, Thier M. An experimental apparatus for the simulation of three-dimensional movements in orthodontics. J Biomed Eng. 1992;14:371-8. 
12. Drescher D, Bourauel C, Thier M. Application of the Orthodontic Measurement and Simulation System (OMSS) in orthodontics. Eur J Orthod. 1991;13:169-78

13. Dellinger EL. A scientific assessment of the straight-wire appliance. Am J Orthod. 1978;73:290-9.

14. Arreghini A, Lombardo L, Mollica F, Siciliani G. Torque expression capacity of 0.018 and 0.022 bracket slots by changing archwire material and cross section. Prog Orthod. 2014;15:53.

15. Lombardo L, Arreghini A, Bratti E, Mollica F, Spedicato G, Merlin M, et al. Comparative analysis of real and ideal wire-slot play in square and rectangular archwires. Angle Orthod. 2015;85:848-58.

16. Sifakakis I, Pandis N, Makou M, Eliades T, Katsaros C, Bourauel C. Torque expression of 0.018 and 0.022 inch conventional brackets. Eur J Orthod. 2013;35:610-4.

17. Thurow RC. Edgewise orthodontics, 4th edn. St Louis: Mosby, 1982. p. 169-171, 329-334.

18. Burstone CJ. The segmented arch approach to space closure. Am J Orthod. 1982;82:361-78.

19. Linge $L$, Linge $B O$. Patient characteristics and treatment variables associated with apical root resorption during orthodontic treatment. Am J Orthod Dentofacial Orthop. 1991;99:35-43.

20. Casa MA, Faltin RM, Faltin K, Sander FG, Arana-Chavez VE. Root resorptions in upper first premolars after application of continuous torque moment. Intra-individual study. J Orofac Orthop. 2001;62:285-95.

21. Burstone CJ. Variable-modulus orthodontics. Am J Orthod. 1981;80:1-16.

22. Halazonetis DJ. Computer experiments using a two-dimensional model of tooth support. Am J Orthod Dentofacial Orthop. 1996;109:598-606.

23. Smith RJ, Burstone CJ. Mechanics of tooth movement. Am J Orthod. 1984;85:294-307.

24. Kaley J, Phillips C. Factors related to root resorption in edgewise practice. Angle Orthod. 1991;61:125-32.

25. Horiuchi A, Hotokezaka H, Kobayashi K. Correlation between cortical plate proximity and apical root resorption. Am J Orthod Dentofacial Orthop. 1998;114:311-8

26. Major TW, Carey JP, Nobes DS, Heo G, Melenka GW, Major PW. An investigation into the mechanical characteristics of select self-ligated brackets at a series of clinically relevant maximum torquing angles: loading and unloading curves and bracket deformation. Eur J Orthod. 2013;35:719-29

27. Sifakakis I, Pandis N, Makou M, Eliades T, Katsaros C, Bourauel C. Torque efficiency of different archwires in 0.018- and 0.022-inch conventional brackets. Angle Orthod. 2014;84:149-54.

28. Sernetz F. Qualität und Normung orthodontischer Produkte aus der Sicht des Herstellers. Kieferorthopädische Mitteilungen. 1993;7:13-26.

29. Meling TR, Odegaard J, Meling EO. On mechanical properties of square and rectangular stainless steel wires tested in torsion. Am J Orthod Dentofacial Orthop. 1997;111:310-20.

30. Gmyrek H, Bourauel C, Richter G, Harzer W. Torque capacity of metal and plastic brackets with reference to materials, application, technology and biomechanics. J Orofac Orthop. 2002;63:113-28.

31. Harzer W, Bourauel C, Gmyrek H. Torque capacity of metal and polycarbonate brackets with and without a metal slot. Eur J Orthod. 2004;26:435-41.

32. Fischer-Brandies H, Orthuber W, Es-Souni M, Meyer S. Torque transmission between square wire and bracket as a function of measurement, form and hardness parameters. J Orofac Orthop. 2000;61:258-65.

33. Partowi S, Keilig L, Reimann S, Jäger A, Bourauel C. Experimental analysis of torque characteristics of orthodontic wires. J Orofac Orthop. 2010;71:362-72.

34. Sifakakis I, Pandis N, Makou M, Eliades T, Katsaros C, Bourauel C. A comparative assessment of torque generated by lingual and conventional brackets. Eur J Orthod. 2013;35:375-80.

35. Pandis N, Strigou S, Eliades T. Maxillary incisor torque with conventional and self-ligating brackets: a prospective clinical trial. Orthod Craniofac Res. 2006;9:193-8.

36. Sifakakis I, Pandis N, Makou M, Eliades T, Bourauel C. A comparative assessment of the forces and moments generated at the maxillary incisors between conventional and self-ligating brackets using a reverse curve of Spee NiTi archwire. Aust Orthod J. 2010;26:127-33.

37. Major TW, Carey JP, Nobes DS, Heo G, Major PW. Mechanical effects of third-order movement in self-ligated brackets by the measurement of torque expression. Am J Orthod Dentofacial Orthop. 2011;139:e31-44.
38. Cattaneo PM, Salih RA, Melsen B. Labio-lingual root control of lower anterior teeth and canines obtained by active and passive self-ligating brackets. Angle Orthod. 2013;83:691-7.

39. Papageorgiou SN, Konstantinidis I, Papadopoulou K, Jäger A, Bourauel C. Clinical effects of pre-adjusted edgewise orthodontic brackets: a systematic review and meta-analysis. Eur J Orthod. 2014;36:350-63.

40. Meling TR, Odegaard J, Segner D. On bracket slot height: a methodologic study. Am J Orthod Dentofacial Orthop. 1998;113:387-93.

41. Joch A, Pichelmayer M, Weiland F. Bracket slot and archwire dimensions: manufacturing precision and third order clearance. J Orthod. 2010;37:241-9.

42. Odegaard J, Meling T, Meling E. An evaluation of the torsional moment developed in orthodontic applications. An in vitro study. Am J Orthod Dentofacial Orthop. 1994;105:392-400.

43. Huang $Y$, Keilig L, Rahimi A, Reimann S, Bourauel C. Torque capabilities of self-ligating and conventional brackets under the effect of bracket width and free wire length. Orthod Craniofac Res. 2012;15:255-62.

44. Hirai M, Nakajima A, Kawai N, Tanaka E, Igarashi Y, Sakaguchi M, et al. Measurements of the torque moment in various archwire-bracket-ligation combinations. Eur J Orthod. 2011;34:374-80.

45. Taloumis LJ, Smith TM, Hondrum SO, Lorton L. Force decay and deformation of orthodontic elastomeric ligatures. Am J Orthod Dentofacial Orthop. 1997;111:1-11.

46. Iwasaki LR, Beatty MW, Randall CJ, Nickel JC. Clinical ligation forces and intraoral friction during sliding on a stainless steel archwire. Am J Orthod Dentofacial Orthop. 2003;123:408-15.

\section{Submit your manuscript to a SpringerOpen ${ }^{\circ}$ journal and benefit from:}

- Convenient online submission

- Rigorous peer review

- Immediate publication on acceptance

- Open access: articles freely available online

- High visibility within the field

- Retaining the copyright to your article

Submit your next manuscript at $>$ springeropen.com 